\title{
Term Pregnancy following Myomectomy for Leiomyomatosis
}

\author{
${ }^{1}$ Suganya Achar, ${ }^{2}$ Arulmozhi Ramarajan
}

\begin{abstract}
Uterine fibroids are common during reproductive age. These are found in up to $77 \%$ of women. They may be asymptomatic or may present with pain, menorrhagia, infertility or recurrent pregnancy loss. Symptomatic fibroids often mandate surgical management. These situations pose a challenge when encountered in women undergoing fertility treatment. Achieving a pregnancy following myomectomy depends on the size, number and proximity to the endometrium of the fibroids.

Here is the case of a 28 -year-old lady, with multiple fibroids, who presented with severe dysmenorrhea and menorrhagia for many years and inability to conceive in 3 years after marriage. She underwent extensive myomectomy. The entire endometrial surface was studded with seedling fibroids, which were scooped out along with much of the endometrium. A diagnosis of uterine leiomyomatosis was made. Three months after surgery, an ultrasound scan of the pelvis showed a bulky uterus of normal contour, endometrial thickness of $7 \mathrm{~mm}$, and multiple tiny fibroids. One year later, she presented with a viable pregnancy of 7 to 8 weeks. She delivered a healthy baby at term.
\end{abstract}

Keywords: Fibroids, Leiomyomatosis, Myomectomy, Pregnancy. How to cite this article: Achar S, Ramarajan A. Term Pregnancy following Myomectomy for Leiomyomatosis. Int J Infertil Fetal Med 2014;5(3):107-109.

Source of support: Nil

Conflict of interest: None

Date of Received: 08-11-14

Date of Acceptance: 14-11-14

Date of Publication: September 2014

\section{INTRODUCTION}

Uterine fibroids are the most common benign uterine tumors during reproductive age. Between 5 and $77 \%$ of women may have fibroids depending on the method of diagnosis used. ${ }^{1}$ Fibroids may remain asymptomatic or may present with menorrhagia, pain, infertility or recurrent pregnancy loss.

In women undergoing infertility treatment, the presence of intramural and submucous fibroids presents

\footnotetext{
${ }^{1}$ Postgraduate Trainee, ${ }^{2} \mathrm{Head}$

1,2Department of Obstetrics and Gynecology, Church of South India Hospital, Bengaluru, Karnataka, India

Corresponding Author: Arulmozhi Ramarajan, Head, Department of Obstetrics and Gynecology, Church of South India Hospital, Bengaluru, Karnataka, India, Phone: 08022861103 e-mail: arulmozhi.ramarajan@gmail.com
}

a clinical challenge. Despite recent studies that have suggested a negative outcome for intramural fibroids on fertility outcome, the evidence remains far from conclusive. ${ }^{2}$ In practice, it is seen that pregnancy can be achieved, in many of these women after surgical removal of the fibroids. The success depends upon the size, number and location of the fibroids.

A case of spontaneous pregnancy resulting in the delivery of a healthy, term baby in a woman following extensive myomectomy for multiple submucous and intramural fibroids is reported here.

\section{CASE REPORT}

A 28-year-old lady, married for 3 years, presented with profuse and painful periods, and inability to conceive. She was anemic, and her gynecological evaluation revealed an irregularly enlarged uterus of 16 weeks size. Ultrasonography showed multiple uterine fibroids with loss of normal architecture and poor endometrial echoes. The largest myoma measured $5 \times 4 \mathrm{~cm}$, and adnexae were normal. Her hemoglobin was $8 \mathrm{~g} / \mathrm{dl}$. Anemia was corrected, and the couple was counseled and prepared for myomectomy. On opening, the uterus was found to be irregularly enlarged to about 16 to 18 weeks gravid uterus size; it was studded with multiple fibroids of varying sizes from 0.2 to $6 \times 6 \mathrm{~cm}$ in diameter. Over 55 myomas (Fig. 1) were removed through a single incision made over the anterior surface of body of the uterus. The uterine cavity was entered while removing myomas that were close to the endometrial cavity. The entire endometrial surface was noted to be studded with seedling fibroids, which had to be scooped out along with much of the endometrium. The uterus was reconstructed, and abdomen closed. A diagnosis of uterine leiomyomatosis was made. A 7-F size Foley's catheter was placed in uterine cavity and its bulb inflated with $3 \mathrm{ml}$ distilled water, to maintain the cavity and prevent adhesion formation. In the immediate postoperative period, the uterine cavity was insufflated with a solution of normal saline $10 \mathrm{ml}$ and injection gentamycin $80 \mathrm{mg}$ and injection hydrocortisone $100 \mathrm{mg}$ on alternate days. The Foley's bulb was deflated and the catheter removed on day 10 of surgery. The patient was given tablet ethinyl estradiol $4 \mathrm{mg} /$ day for 20 days for inducing endometrial growth and to prevent 
formation of uterine synechiae. She was given combined oral contraceptive pills for three cycles to promote cyclical endometrial regeneration and withdrawal bleeds. Three months after surgery, an ultrasound scan of the pelvis showed a bulky uterus of normal contour, endometrial thickness of $7 \mathrm{~mm}$, and multiple tiny fibroids. One year later, the lady reported with a missed period. Ultrasound examination confirmed a single, live intrauterine gestation of about 7 to 8 weeks. She presented with vaginal bleeding at 8 and 15 weeks of gestation. She developed gestational hypertension and gestational diabetes mellitus that were managed with medication and close monitoring. At 38 weeks, she was admitted with history of watery discharge per vaginum. Examination revealed a relaxed uterus, with the fetus in breech presentation; the cervix was uneffaced, os closed, with active leak of clear amniotic fluid. An emergency cesarean section was done. She delivered a healthy baby with good Apgars (Fig. 2). The cesarean incision site showed multiple small to medium fibroids, some of which were removed (Fig. 3). The site of myomectomy incision on the uterus

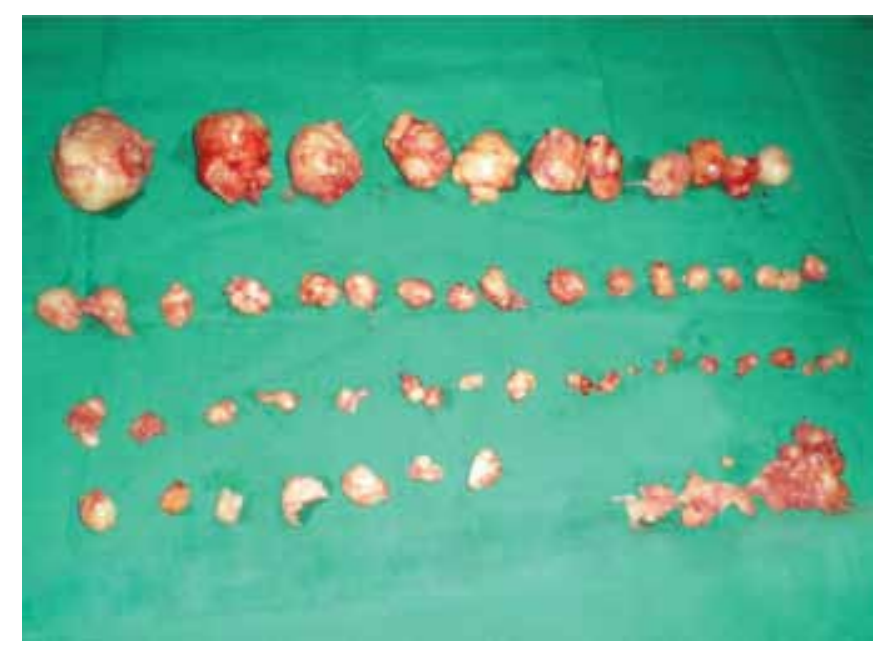

Fig. 1: Fibroids removed at myomectomy

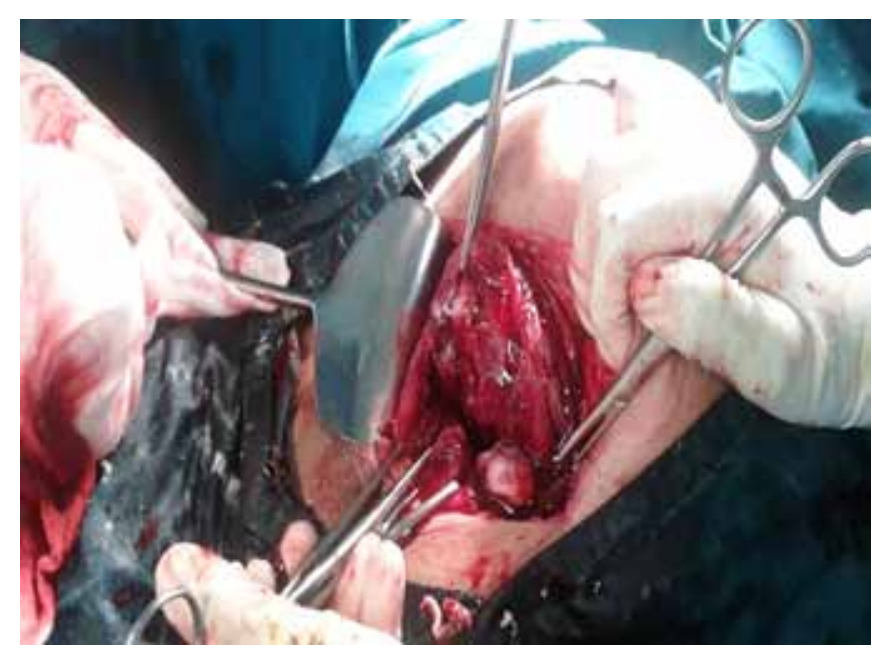

Fig. 3: Multiple fibroids at uterine incision site was healthy, with no evidence of scarring or thinning of the myometrium. The entire uterine cavity was bosselated on palpation, with innumerable small submucous fibroids. Postoperative period was uneventful. Mother and baby went home well (Fig. 4).

\section{DISCUSSION}

Myomectomy has an excellent record in reducing heavy menstruation in patients reporting menorrhagia. In more than $80 \%$ of patients, menorrhagia is cured or significantly improved. Pelvic pain and discomfort and dysmenorrhea can also be relieved. But, there are limitations when it comes to fertility enhancement following myomectomy. In a woman with uterine leiomyomata, a number of factors may be responsible for subfertility:

- Interference with sperm transport caused by distortion and an increased surface area within the uterine cavity.

- Impingement of leiomyomata on the endocervical canal or interstitial portion of the fallopian tube.

- Interference with prostaglandin-induced uterine contractions, which are thought to enhance sperm migration.

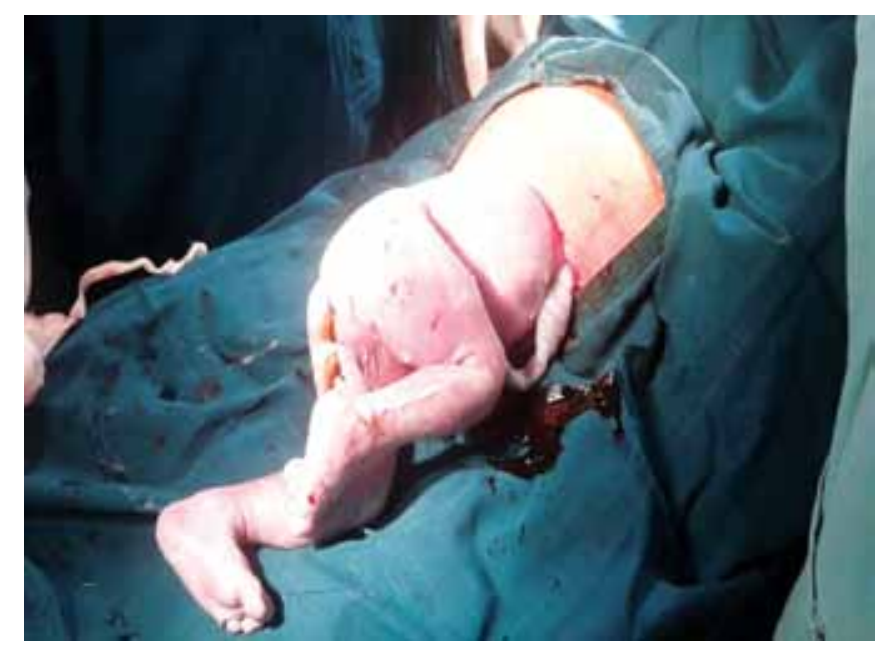

Fig. 2: Lower segment cesarean section, baby delivered as breech

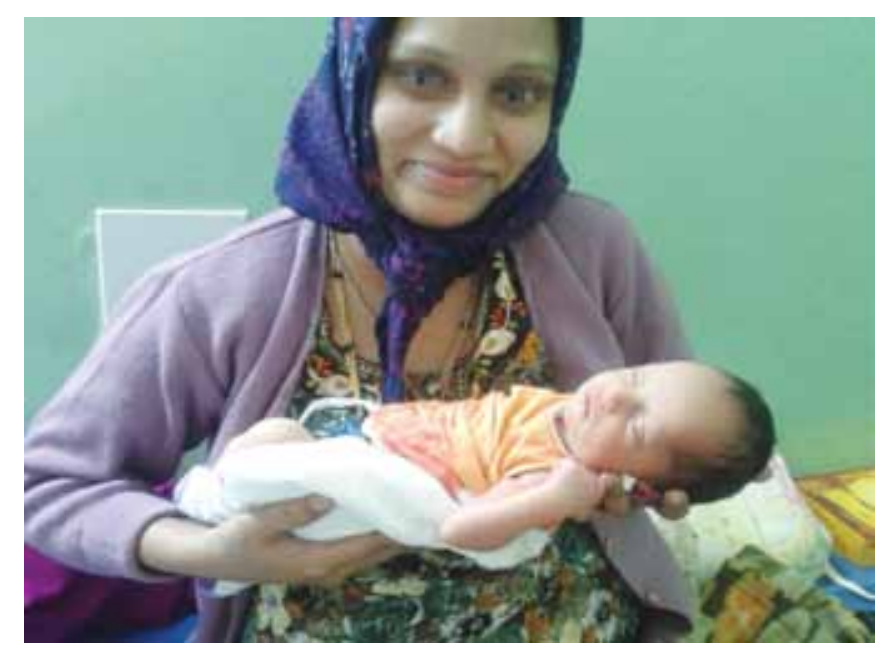

Fig. 4: Healthy mother and baby 
- Endometrial changes (atrophy, ulceration, focal hyperplasia, and polyps).

- Vascular alterations (venous congestion, venule ectasia, impaired blood flow) may be present.

Before offering myomectomy to enhance fertility, it is important to exclude other causes of infertility in the couple. The husband should have a complete infertility investigation before deciding for myomectomy. ${ }^{3}$ Buttram and Reiter reviewed 1699 cases of myomectomy and determined that $27 \%$ of these women also had infertility. ${ }^{4}$ When all the other causes were ruled out, myomas were found to play a role in only $2.4 \%$ of the cases. Hence, it was concluded that, although myomas may be co-incidentally present in $25 \%$ of cases of infertility, myomectomy would directly benefit only $2.4 \%$ of these women, where all other infertility factors have been ruled out.

Not all infertile women benefit from removal of fibroids. Myomectomy could also lead to peritubal adhesions and distortion of the tubo-ovarian relationship. Removal of submucous fibroids may lead to intrauterine adhesion formation. These fallouts can reduce the chances for pregnancy. Hence, the decision to perform myomectomy or not in an infertile patient with fibroids is a crucial one. Pregnancy following resection of multiple submucous and intramural fibroids has been reported. ${ }^{5}$

A meta-analysis of women with long-term unexplained infertility and myomas demonstrated a conception rate of $59.5 \%$ after myomectomy and the majority of these conceptions occurred within 1 year of surgery. ${ }^{6}$ Beyond one year of surgery, fibroids may recur, and this could hinder conception. In a retrospective analysis of 51 women with no uterine cavity distortion authors observed a significantly higher pregnancy rate of $76 \%$ after myomectomy vs 40\% before myomectomy. ${ }^{7}$ Myomectomy may be performed by either an open abdominal approach or laparoscopic approach; both have shown comparable outcomes with regard to conception and pregnancy outcome.

In Verkauf's review myoma recurred in $7.5 \%$ of the patients. Most recurrences appeared more than 3 years after myomectomy, thus allowing sufficient time for conception to occur before recurrence. ${ }^{8}$ The patient reported here achieved pregnancy in a year's time. She also developed recurrent fibroids, but these did not hinder spontaneous conception and pregnancy.

\section{CONCLUSION}

In this case report, the extensive myomectomy was performed mainly for the symptoms of menorrhagia and dysmenorrhea. The procedure incurred much loss of endomyometrium along with the fibroids. Avoidance of hysterectomy, intrauterine adhesion prevention and the occurrence of normal menses were the immediate hope and goals. Spontaneous conception happened against many odds, and the pregnancy continued to term. The uterus appeared healthy with no evidence of any thinning or scarring over the anterior wall that was the site of the myomectomy incision. Multiple fibroids, however, had recurred.

\section{REFERENCES}

1. Lethaby A, Vollenhoven B. Fibroids (uterine myomatosis, leiomyomas). Clinical Evidence (Online) Jan 2011. PII. 0814. National Institute of Health's National Library of Medicine (NLH/NLM).

2. Metwally M, Farquhar CM, Chiu Li T. Is another meta-analysis on the effects of intramuscular fibroids on reproductive outcomes needed? International Federation of Fertility Societies, Elsevier, Published online Oct 2012. p. 2-14. Reproductive BioMedicine Online 2011;23:2-14.

3. Breech LL, Rock JA. Leiomyoma uteri and myomectomy. In: Rock JA, Jones HW 3rd, editors. Te Linde's Operative Gynecology. 10th ed. Philadelphia: Lippincott Williams and Wilkins 2008. p. 688-727.

4. Buttram VC Jr, Reiter RX. Uterine leiomyomata: etiology, symptomatology and management. Fertil Steril 1981 Oct;36(4): 433-445.

5. Kavneet G, Abha M. Live birth following resection of multiple submucous myomas: a unique case report. J Obstet Gynecol India 2012 Mar-Apr;62(2):195-196.

6. Elder-Geva T, Meagher S, et al. Effect of intramural, subserosal and submucosal uterine fibroids on the outcome of assisted reproductive technology treatment. Fertil Steril 1998;70:687-691.

7. Li TC, Mortimer R, Cooke ID. Myomectomy: a retrospective study to examine reproductive performance before and after surgery. Human Reprod 1999 July;14(7):1735-1740.

8. Verkauf BS. Myomectomy for fertility enhancement and preservation. Fertil Steril 1992 July;58(1):1-15. 